\title{
AMENDMENTS
}

\section{Author Correction: Depletion of aneuploid cells in human embryos and gastruloids}

Min Yang, Tiago Rito, Jakob Metzger, Jeffrey Naftaly, Rohan Soman, Jianjun Hu, David F. Albertini(D, David H. Barad, Ali H. Brivanlou (iD and Norbert Gleicher (iD)

Correction to Nature Cell Biology https://doi.org/10.1038/s41556-021-00660-7, published 9 April 2021.

In the version of this Letter originally published online, Supplementary Table 1 included 9 of the 32 patients in this study who received chromosomally 'abnormal' embryos. The originally published table included only those 9 patients who achieved pregnancy. We here provide an updated and corrected version of the table including all 32 patients. In addition, during the manuscript preparation process, a transcription error regarding patient 7 occurred, listing one of the transferred embryos as $47, \mathrm{XX},+21$ (Down syndrome), which we would not recommend for transfer and did not transfer. The actual transferred embryo was a mosaic trisomy- 9 embryo with karyotype $47, \mathrm{XX},+9$ [mos], which has now been corrected in the revised Supplementary Table 1 . We furthermore received clinically relevant updates on patients 1 and 5. Patient 5 upon amniocentesis was initially reported as having a normal 46,XY pregnancy. Only after the foetus was diagnosed in utero by ultrasound with a coarctation of the aorta were further chromosomal studies done, which identified the deletion originally reported in a transferred embryo. The chromosomal status of the newborn was therefore corrected in the revised Supplementary Table 1, with the newborn deemed healthy after neonatal correction of the coarctation. Finally, based on oral reports from the patient, the information for patient 1 was amended to indicate embryos with karyotypes of 45,XY,-22 and 47,XY,+12. When a subsequent written report was received, the embryos were listed as $45, \mathrm{XX},-22$ and $47, \mathrm{XY},+12$ [mos], now reflected in a further correction made in the revised Supplementary Table 1 . None of these changes affect the conclusions reached in the manuscript.

The original Letter has been corrected in the online version of the paper.

Published online: 21 September 2021

https://doi.org/10.1038/s41556-021-00775-X

(c) The Author(s), under exclusive licence to Springer Nature Limited 2021

\section{Author Correction: Diverse heterochromatin-associated proteins repress distinct classes of genes and repetitive elements}

Ryan L. McCarthy, Kelsey E. Kaeding, Samuel H. Keller DiD, Yu Zhong (D), Liqin Xu (D), Antony Hsieh, Yong Hou, Greg Donahue, Justin S. Becker (iD, Oscar Alberto, Bomyi Lim and Kenneth S. Zaret (D)

Correction to: Nature Cell Biology https://doi.org/10.1038/s41556-021-00725-7, published online 5 August 2021.

In the version of this Article initially published, the Acknowledgements text reading "A.H. was supported by the American Society of Clinical Oncology Young Investigator Award" has been changed to read "A.H. was supported by the Conquer Cancer, ASCO Foundation Young Investigator Award."

The original Article has been corrected online.

Published online: 29 September 2021

https://doi.org/10.1038/s41556-021-00759-X

(c) The Author(s), under exclusive licence to Springer Nature Limited 2021 